\title{
P02-03. Screening of potential adjuvants for induction of pro-IgA
}

\section{factors}

\author{
V Buffa*1, K Klein ${ }^{2}$, J Tregoning ${ }^{1}$, A Siddiqui ${ }^{1}$ and R Shattock ${ }^{1}$
}

Address: ${ }^{1}$ St George's University of London, London, UK and ${ }^{2}$ SGUL, London, UK

* Corresponding author

from AIDS Vaccine 2009

Paris, France. 19-22 October 2009

Published: 22 October 2009

Retrovirology 2009, 6(Suppl 3):P8 doi:10.1 I86/I 742-4690-6-S3-P8

This abstract is available from: http://www.retrovirology.com/content/6/S3/P8

(C) 2009 Buffa et al; licensee BioMed Central Ltd.

\section{Background}

Mucosal epithelial cells may play a critical role in maintaining the balance between tolerance and induction of IgA response. Current data suggests this homeostatic balance may be regulated by the production of epithelial proteins, including thymic stromal lymphopoietin (TSLP) induced through Toll-like receptors. TLR ligands are also thought to play an important role in the activation induction of pro- (or anti-) IgA factors by subepithelial dendritic cells and B cells including TGF-beta, IL-4 and APRIL. In this study we have evaluated a broad range of TLR ligands in mucosal cellular models and in human genital tissue explants for the induction of immunomodulatory cytokines known to influence IgA induction.

\section{Methods}

ME180, HT29 and HEC1a cell lines were used as representative examples of vaginal and rectal epithelial cells. In addition both human cervical and penile explants were used to assess human genital tissue cytokine response to TLR ligands. Tissue explants and cell lines were exposed to TLR ligands for 24 hours and supernatants analysed by Luminex assay.

\section{Results}

The profile of cytokine secretion by the different cell lines and tissue explants tested demonstrated reactogenicity to a range of TLR candidates. In particular, LPS (TLR4), peptidoglycan (TLR2), Poly I:C (TLR3), Flagellin (TLR5), FSL1 (TLR2 and 6) and CpG (TLR9) were all able to induce a distinct cytokine profile including the induction of proIgA cytokines IL-1-beta GM-CSF and TGF-beta.

\section{Conclusion}

Characterization of the cytokine profile induced by the evaluated TLR ligands in both cellular and human genital tissue models may be critical to developing mucosal adjuvants designed to induce and maintain mucosal IgA responses to HIV. A pilot in vivo study in mice has evaluated their potential for promoting IgA induction when using mucosal immunization routes. 